\title{
Psycho-physiological mechanism of energy transfer in the human body: myth or reality?
}

The authors consider the existence of an energy transfer
system (ETS) in the human body and its consequences for
health, performing a review of the available literature and
studies. The article is an attempt to describe the possible
psychophysiological mechanism of ETS (i.e. mechanism
of transmission of stimuli in connective tissue) based on
biochemical reactions, which was first described in East-
ern Medicine a long time ago. Some previously reported
results suggest that it is possible to modulate the psycho-
physiological effects on the connective tissue, and that the
internal ETS can be activated not only through internal
acupoints but also through breath self-regulation tech-
niques. Among the people specialized in such breathing are martial art fighters. In a very preliminary pilot study we investigate four cases in a Vietnamese Thiên Môn Đạo (TMD) group, where breathing techniques result in cardiovascular and blood pressure changes, which can indirectly suggest activation of ETS. An additional energy system in the human body is postulated. However, future research is seriously needed. Findings could be applicable e.g. in cardiac rehabilitation programs.

\section{KEY WORDS}

health psychology; energy transfer system (ETS); psychopsychological functioning; Vietnamese martial art school

ORGANIZATION - 1: Department of Biochemistry, National Institute of Geriatrics, Rheumatology and Rehabilitation,

Warsaw, Poland · 2: Institute of Psychology, University of Gdansk, Gdansk, Poland · 3: Institute of Psychology,

Vietnam Academy of Social Sciences, Hanoi, Vietnam

AUthors' Contributions - A: Study design - B: Data collection - C: Statistical analysis · D: Data interpretation .

E: Manuscript preparation · F: Literature search · G: Funds collection

CORRESPONDING AUthor - Prof. Joanna Różycka-Tran, Institute of Psychology, University of Gdansk, 4 Bażyńskiego Str., 80-952 Gdansk, Poland, e-mail: joanna.tran@ug.edu.pl

To Cite this ARTICLE - Gajewski, M., Różycka-Tran, J., \& van Le, H. (2019). Psycho-physiological mechanism of energy

transfer in the human body: myth or reality? Health Psychology Report, 7(4), 267-275. https://doi.org/10.5114/

hpr.2019.88624

RECEIVED 05.07.2019 • REVIEWED 12.09.2019 · ACCEPTED 12.09.2019 • PUBLISHED 16.10.2019 


\section{AN ENERGY TRANSFER SYSTEM IN THE HUMAN BODY?}

Psychological sciences search for a full description of the psycho-physiological functioning of the human body in the case of homeostasis. Homeostasis depends on propagation of information, which synchronizes functions of different tissues. The problem is that western science (i.e. medicine or psychology) is based on three coordinating systems - nervous, hormonal, and lymphatic - whereas an additional energy transfer system (ETS) in the human body was described many years ego in traditional Chinese medicine (TCM).

Conducted studies suggest that the connective tissue (CT) may be considered in Western medicine to be part of the fourth system of information exchange and an ETS that may affect both physiological and pathophysiological functions (Gajewski et al., 2006; Gajewski \& Maśliński, 2012, for review).

Some western scientists from Necker Hospital in Paris have already proved the existence of an ETS in the human body. The authors investigated the pathways of acupuncture points (i.e. structures of CT that Chinese medicine considers to be the pathways of Qi energy flow) in the human body through the injection of radioactive technetium tracers (isotopes) at acupuncture points (Darras, de Vernejoul, \& Albarede, 1992). Morphological studies found those tracers' migrations from acupoints in both 250 healthy and 80 sick patients (but not the dead body), following pathways identical to those described as meridians in Asian traditional medicine. The migration speed and patterns of a radioactive tracer along pathways which coincide with the Asian acupuncture points show that these routes are different from vascular and lymphatic pathways described in modern medicine (Darras et al., 1992).

Moreover, studies of Takewaki et al. (2003) show that stimulation of the same acupoints (mainly ST-36) with the help of acupuncture needles may have a completely opposite effect on the activity of the digestive system in different situations. In the case of the initially stimulated gastrointestinal motility, the effect of acupuncture was inhibitory, while in the case of slowed motility, the effect was even stimulating. These observations are consistent with the view of TCM, according to which acupuncture rebuilds the balance of yin and yang, thus restoring the body to a state of metabolic balance - homeostasis (Takewaki et al., 2003).

It seems that acupuncture therapy is based on the principle of restoring equilibrium of the body's energy state in the corresponding meridians and acupoints. These results suggest that there may be bioenergy (Qi) transfer during acupuncture along the meridians, and this transferred bio-Qi seems to act as an electromotive force, which is purported to remove the stagnation or blockage of energy and restore an equilibrium state (Lee et al., 2005). According to Eastern philosophy and medicine, Qi energy represents an invisible life force underlying all phenomena. Qi is believed to be a vital force forming part of any living entity. Qi is the central underlying principle in Chinese traditional medicine and in Chinese martial arts translates as "air", "material energy", "life force", or "energy flow". In Western science Qi energy seems to be movement of electrons between molecules present in cells. It is important to note that some studies indicate that the internal ETS can be activated not only through internal acupoints but also by external breathing techniques.

\section{MODULATION OF PHYSIOLOGY BY MIND-BODY THERAPIES}

It is commonly accepted that the vascular-neuroendocrine-lymphatic network, coordinating human metabolism, can be regulated through self-regulation, e.g. breathing techniques (Bower \& Irwin, 2016; Różycka \& Tran, 2012).

Many studies have confirmed that the use of mindbody therapies (MBT), including yoga and meditation, is effective in reducing symptoms of different biological processes, including inflammation (Bower \& Irwin, 2016). Significant differences in pro-inflammatory cytokines have been observed between practitioners and non-practitioners of yoga in response to exercise challenge, for example, regular yoga practice reduces resting levels of inflammatory mediators (Irwin et al., 2015; Vijayaraghava, Doreswamy, Narasipur, Kunnavil, \& Srinivasamurthy, 2015).

As was shown by Dada, Kumar, Chawla, Bisht, and Khan (2016) yoga and meditation cause a significant decline in oxidative stress (OS) and oxidative DNA damage (ODD) and aid in regulating OS levels such that reactive oxygen species mediated signal transduction, gene expression and several other physiological functions are not disrupted. This study reports a decline in OS and ODD and improvement in sperm DNA integrity following adoption of meditation and yoga based life style modification. This may reduce disease burden in the next generation (Dada et al., 2016) and suggested the influence of yoga even on subsequent generations.

Moreover, recent studies showed that yoga and meditation were efficacious in reducing levels of oxidative stress (extensive oxygen radical production) and cellular aging in obese men. It was suggested that yoga and meditation cause a reversal of markers of aging, mainly oxidative stress, telomerase activity, and oxidative DNA damage that may finally delay the aging process in living organisms (Kumar, Yadav, Yadav, Tolahunase, \& Dada, 2015).

There is growing evidence in the literature examining the effects of MBT on cholinergic system ac- 
tivity during inflammatory processes (Singh, Khandelwal, \& Sherpa, 2015; Tracey, 2009). These results suggest that the consequences of these approaches may initially be reflected in alterations in gene expression profiles and indicators of pro-inflammatory signaling. It should be noted that these alterations in inflammatory gene expression were identified after relatively short (six weeks) interventions of MBT on cholinergic activity (Bower \& Irwin, 2016).

Our previous studies have shown that it is cholinergic (parasympathetic nervous system - PSNS), and not adrenergic (sympathetic nervous system - SNS), stimulation that is responsible for the processes modulating energy flow under pathological conditions (Gajewski, Laskowska-Bożek, Maśliński, \& Ryżewski, 1991; Gajewski, Laskowska-Bożek, Moutiris, Maśliński, \& Ryżewski, 1993; Gajewski et al., 2006; Gajewski, Maśliński, Rzodkiewicz, \& Wojtecka-Łukasik, 2013, for review).

Adrenergic stimulation results in bringing the body to a state of raised activity and attention, usually called the "fight or flight" response. In contrast, stimulation of the cholinergic system can be summarized as the "rest and digest response", as this returns the body functions back to normal (Gajewski et al., 2013, for review). The cholinergic system consists mainly (75\%) of the vagus nerve, which is the largest nerve and owes its name to the wandering course along the body. Since the activity of the vagus nerve can be relatively easily modulated by modified respiratory processes (abdominal breathing), it can be assumed that the body's energy metabolism could also be modified in this simple manner (Gajewski et al., 2006; Gajewski et al., 2013).

Finally, it seems that MBT decrease adrenergic neural system activity (fight or flight) and reduce blood pressure (BP) with a parallel increase of cholinergic activity (rest and digest) (Unger, Paulis, \& Sica, 2011). In conclusion, relaxation by yoga training is associated with a significant increase of cardiac vagal modulation. Since this method is easy to apply, it could be a suitable intervention in cardiac rehabilitation programs (Khattab, Khattab, Ortak, Richardt, \& Bonnemeier, 2007).

The practice of yoga is proposed to alter the autonomic nervous system and affect cardiovascular functioning. Autonomic balance tilts toward cholinergic predominance just after one month practice of yoga. As was noted, these changes as a result of MBT were observed after a very short time (Vinay, Venkatesh, \& Ambarish, 2016; Khattab et al., 2007).

Moreover, any stressful situation affects the balance between adrenergic and cholinergic systems. This response is a classic "fight or flight" response, which is the mobilization of energy. Yoga attenuated the stress cascade by reducing the perception of stress. MBT decreases physiological manifestation of stress by lowering heart rate, blood pressure, and re- spiratory rate, via cholinergic activation (Singh et al., 2015).

In general terms, MBT are associated with decreases in adrenergic activity and increases in cholinergic activity, reflecting a greater sympatho-vagal balance. These observations have been made at rest, following the practice of the technique, and in response to acute stress. Increases in cholinergic activity may also reduce inflammation via the cholinergic anti-inflammatory pathway (Tracey, 2009).

\section{POSSIBLE MECHANICAL AND BIOELECTRICAL MECHANISM \\ OF TRANSMISSION OF STIMULI IN CONNECTIVE TISSUE}

Acupuncture is an unconventional technique for treatment that came from the East but it seems that similar techniques were used in ancient Europe and America - ancient mummies (stone aged) that have tattoo lines partly overlapping meridians were discovered in Europe ("Ice Man") (Dorfer et al., 1998).

Eighty percent of correspondence was found between the sites of acupuncture points and the location of intermuscular or intramuscular CT planes in postmortem tissue sections. It was hypothesized (Langevin \& Yandow, 2002) that the network of acupuncture points and meridians can be viewed as a representation of the network formed by interstitial CT. Transmission of stimuli (mechanical, bioelectrical and biochemical) through CT may have a powerful potential for integration across physiological systems (CT surrounds all the organs, nerves, blood vessels and lymphatic) and between different parts of the body (Langevin, Churchill, \& Cipolla, 2001).

Mechanical stimulus of the meridian can be transduced into bioelectrical and/or biochemical signals and can lead to downstream effects, including cellular actin polymerization, signaling pathway activation, changes in gene expression, protein synthesis, and extracellular matrix modification (Langevin \& Yandow, 2002). Actin polymerization in CT fibroblasts may cause further pulling of collagen fibers and a "wave" of CT contraction and cell activation spreading through CT during acupuncture treatment (Langevin et al., 2001).

Moreover, excitable nerve-like structures that express spontaneous electrical activity have been found in the newly discovered system called the primo vessel system (PVS). The contractility of PVS is slowed by the activation of cholinergic receptors (Chikly, Roberts, \& Quaghebeur, 2016). Moreover, Lee et al. (2006) and Soh (2004) suggested that PVS can be a good medium to transport or communicate tissue bioluminescence (biophoton). It seems that only primo fluid in PVS fully circulates through the whole body of living organisms (Stefanov, 2012). It was later found that the direction
An energy system in the human body 
Michał Gajewski, Joanna RóżyckaTran, Hao van Le of primo fluid flow was independent of the direction of blood flow (Stefanov 2012; Stefanov \& Kim, 2012). Arterial blood flow goes to the tissues, and venous blood and lymphatic fluid go to the heart, whereas the primo fluid fully circulates through the whole body. A new vision of the anatomical basis for PVS and vital energy - called "Qi" - like an electromagnetic wave in the PVS was proposed (Stefanov, 2012). All the PVS for the organs is connected to all meridians. It was shown that each meridian structure starts and ends at the PVS for the organs. In following the vessels and the nerves, the PVS uses these structures as a type of "highway" and as a way to influence body systems and organs (Stefanov et al., 2013).

The human body is more than the atoms and molecules that make up our tissues or organs, as humans are beings of light as well. Light emission has been correlated with cerebral energy metabolism and oxidative stress within organs of living organisms, with a visibility 1,000 times lower than the sensitivity of human eyes, and being detectable only via sophisticated instrumentation (Kobayashi et al., 1999; Kataoka et al., 2001). Emission of these biophotons by the human body is known as ultraweak photon emission (UPE) (Niggli et al., 2005; Slawinski, 2005).

Because the metabolism of the body changes in a circadian fashion, UPE also varies along the axis of diurnal time; generally the fluctuation in UPE over the body is lower in the morning than that in afternoon (Kobayashi, Kikuchi, \& Okamura, 2009). It has been demonstrated that the UPE of healthy persons was different over body sites, and photon intensity varied in different physiological and pathological states (Lee et al., 2004). It seems that the cells and tissues use biophotons to store and communicate information in the body of living organisms. It was demonstrated that light stimulation at one end of the spinal sensory or motor nerve roots resulted in a significant increase in the biophotonic activity at the other end. It suggested that light stimulation can generate biophotons that are conducted along the neural fibers, probably as neural communication signals (Sun, Wang, \& Dai, 2010). Wanga, Wanga, Lia, Xiaoa, and Daia (2016) provided experimental evidence that glutamate-induced biophotonic activities and transmission in brain slices present a spectral redshift feature from animals (bullfrog, mouse, chicken, pig, and monkey) to humans, which may be a key biophysical basis for explaining why human beings have higher intelligence than that of other animals. Moreover, the lowest UPE intensities were observed in subjects who regularly meditate (van Wijk, Koch, Bosman, \& van Wijk, 2006). It was found that patients who took the herbs used in TCM for 1 week had a significant decrease in UPE comparison with the placebo group (Schutgens et al., 2009).

Analogically to acupuncture, the PVS, like the connective tissue, seems to be activated through breath self-regulation techniques.

\section{GASOTRANSMITTERS AS POSSIBLE DECISIVE FACTORS IN ENERGY TRANSFER SYSTEM}

In coordinating the activity of the cholinergic system, the sensory nucleus of the vagus nerve located in the brain stem (nucleus tractus solitarius - NTS) plays an important role. It receives stimuli from both somatic and internal organs. It seems that nerve impulses could positively or negatively affect the NTS nucleus, which would then transmit stimulatory or inhibitory stimuli to the viscera with identical input stimuli. Therefore, it can be concluded that when the parasympathetic nerve is activated, acupuncture can trigger a sympathetic response that will counteract the parasympathetic system, and thus lead to inhibition of gastrointestinal motility. By contrast, when the sympathetic nerve is active, acupuncture activates the opposite system of the parasympathetic system, stimulating peristalsis, thus maintaining the homeostasis of the body. These results finally indicate that acupuncture affects the activity of physiological processes, at least to a certain extent via parasympathetic cholinergic fibers (Lee et al., 2005; Takewaki et al., 2005).

According to modern knowledge, it is actually accepted that the three gases, commonly known as a toxic gases, carbon monoxide (CO), nitric monoxide $(\mathrm{NO})$, and hydrogen sulfide $\left(\mathrm{H}_{2} \mathrm{~S}\right)$, are generated endogenously in living organisms by stimulating receptors of the cholinergic system (Mustafa, Gadalla, \& Snyder, 2009; Szabo, 2010). It was shown that cytochrome oxidase (COX), the terminal enzyme of the mitochondrial complex, is a mediator of the energy producing system not only through its natural ligand, $\mathrm{O}_{2}$, but also through the binding of cholinergic gasotransmitters such as $\mathrm{CO}, \mathrm{NO}$, and $\mathrm{H}_{2} \mathrm{~S}$, and finally may partially reduce energy production by living organisms (Szabo, 2010).

In previous studies, we postulated that these cholinergic gasotransmitters may be a part of the system commonly known in eastern medicine and philosophy as a yin/yang system. The $\mathrm{O}_{2}$ stimulation metabolism factor may be recognized as a yang factor (hot, accelerating, enhancing), contrary to $\mathrm{CO}, \mathrm{NO}$, and $\mathrm{H}_{2} \mathrm{~S}$ inhibiting metabolism factors, which may be recognized as yin factors (cold, inhibiting, weakening) (Gajewski et al., 2006; Gajewski et al., 2013, for review), see Figure 1.

For example, hibernation is a state of the body in which metabolic processes are inhibited but do not result in termination. It was shown that the effect of "suspended animation" is likely related to the inhibition of mitochondrial electron transport, and finally energy production, mainly by a high local concentration of $\mathrm{H}_{2} \mathrm{~S}$. Moreover, $\mathrm{H}_{2} \mathrm{~S}$ is balanced and the role of $\mathrm{H}_{2} \mathrm{~S}$ in hibernation is related to an endogenously controlled shift in the way it is produced and consumed 
(Revsbech et al., 2014). It was suggested that these complementary abilities of gasotransmitters such as $\mathrm{H}_{2} \mathrm{~S}$ and NO may induce controlled and reversible hypometabolic states (Revsbech et al., 2014).

Moreover, since body electricity depends on neural activity and its stimulation (e.g. by purely mechanical activation of one's own muscles) may be triggered or additionally enhanced via gasotransmitter release, it seems that these gasotransmitters can be regarded as a decisive factor in energy metabolism (Ma, Li, Sakurai, \& Pandjaitan, 2007).

Therefore, control over energy flow in the human body would not be at all impossible. It may be assumed that different types of acupuncture with different effects, modulating the activity of one's muscles, can significantly modify the physiology of the body. As it was found in some studies (Hui, Pei-Jing, \& Liang, 2010), acupuncture (exogenously inserted needles) can be used to modulate energy metabolism in selected regions of the body. It can be assumed that maybe cough or broader breathing modulations (endogenous effects via own muscle tension modulation) can be used for a sort of "self-acupuncture" (Hui et al., 2010). Moreover, electro-acupuncture, a modified form of acupuncture, was found to significantly increase vagus nerve activity (Pavlov \& Tracey, 2012; Oke \& Tracey, 2009). It was shown that different types of acupuncture, and in consequence, different types of pressure, can cause production of cholinergic gasotransmitters (such as $\mathrm{H}_{2} \mathrm{~S}$ ) or their release of varying intensity, which as a result causes varied cholinergic activity (Hui et al., 2010).

\section{ACTIVATION OF ENERGY TRANSFER SYSTEM THROUGH BREATHING TECHNIQUES: THIÊN MÔN ĐAO MARTIAL ART STUDY}

People specialized in such breathing include martial art fighters, such as Thiên Môn Đao (TMD, translation: Heaven's Gates) - a traditional martial arts school in Vietnam, founded in the $18^{\text {th }}$ century. Even children study the most advanced techniques in a short time (two 2-hour training sessions a week for two years), difficult kung-fu exercises such as breaking a block weighing 80 kilos on a bending human body; resisting and bending an iron rod at such key nerve points as the navel and the pharynx and smashing a pile of bricks placed on one hand with the other hand; striking nails into muscles without bleeding and pulling a 2.5 -tonne van by a rope tied to the nail. Practicing exactly the same exercises, in due course they attain the standard of performance with similar capabilities.

According to the philosophy of TMD (and other similar schools), each person has great potential, but only a few use it fully. One aspect of this potential

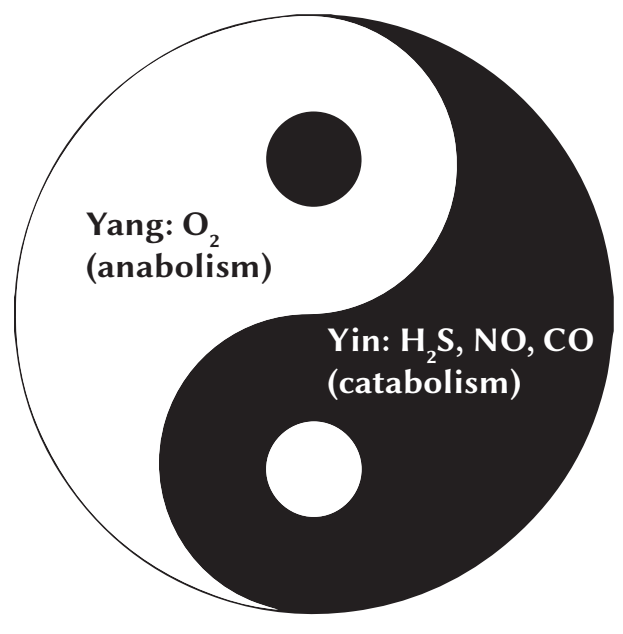

An energy system in the human body
Figure 1. Gasotransmitters as an essential part of the anabolism/catabolism system in Western medicine and the yin/yang system in traditional Chinese medicine.

is the ability to affect one's own psycho-physical processes, which can also be used to fight diseases. TMD self-regulatory techniques are based on controlling the flow of Qi energy in the body. TMD adepts can control Qi energy, spreading it around the body along the system of meridian channels, which causes that a practitioner can affect their own muscles - activating one, deactivating another - thus generating additional energy resources, observable in action.

What is interesting, all TMD self-regulation techniques (activating Qi energy) are based on different types of breathing (e.g. like a child in the womb, like a frog, turtle, stork) - to live longer and healthier than the average human, which allow quick modification of metabolism by very fast chemical modifications. Such breathing and concentration exercises, combined with a special arrangement of physical movements, result in maximum sharpening of the senses, enabling reception and interaction with external forces through extrasensory experiences such as infrared and ultraviolet radiation, air pressure or a magnetic field (Włodarski \& Stankiewicz, 2012).

Our preliminary studies, using monitors to measure blood pressure, conducted in 2009-2011 on a TMD group, showed that the adepts could change both their heart rate and blood pressure parameters. We used automatic blood pressure monitors to measure the pulse and heart rate, before and after a short 10-second breathing technique. After five seconds of concentration, almost everybody from the group could increase and decrease their heart rate efficiently, as is described in detail in another article (see Różycka \& Tran, 2012).

Based on our preliminary finding, we again conducted the study in the Thiên Môn Đạo school, in cooperation with a nearby hospital, using both Holter 
Michał Gajewski, Joanna RóżyckaTran, Hao van Le

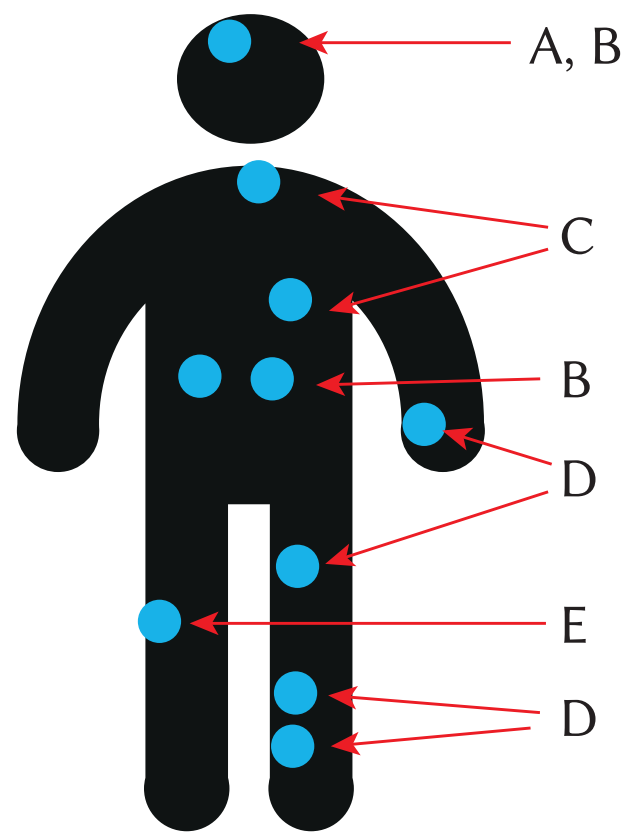

Figure 2. The therapeutic approach based on Western medicine and traditional Chinese medicine methods: A - meditation, hypnosis, B - immediate/mediate stimulation of vagal nerve, $\mathrm{C}$ - anti-rheumatic drugs, D - acupuncture, E - cholinergic agonists.

Source: Maśliński \& Ryżewski, 2009.

and automatic blood pressure monitoring. All impressive abilities were recorded ${ }^{1}$ such as: bending rods with the nose or throat, lifting three plastic buckets filled with water with an eyelid, pulling cars using a rope and nails pierced under the skin (with no signs of bleeding and skin tearing). After short exercises we went to the hospital, where a few of adepts were connected to the Holter and ECG system, where we noticed significant cardiovascular changes ${ }^{2}$. Normal heart function (as demonstrated by Holter and ECG readings) during sudden blood pressure increases was observed, indicating significantly increased cardiac output (without tachycardia or ventricular fibrillation during rapid heart rate). The absence of a pulse in wrist arteries with a maintained pulse in carotid arteries confirms the sudden increase in diastolic blood pressure (the blood does not reach small peripheral arterioles). We noted that TMD adepts were able to influence the heart and pulse rate, i.e. consciously increasing or decreasing it.

\section{DISCUSSION AND CONCLUSIONS}

According to the TMD, there are techniques for redirecting life energy within the body which everyone can learn as self-healing abilities. It is possible that self-healing is consistent with the contemporary state of knowledge and available to everyone, after training. In western science Qi energy may be defined as energy of chemical reactions, i.e. oxidation and reduction, which is nothing other than the movement of electrons. The present preliminary results suggest that through breathing it is possible to change the level of gasotransmitters and/or light intensity in connective tissue, and thus levels of adrenergic and cholinergic neurotransmitters in acupoints. The analysis of different data, although only partially recognized by Western science, may also suggest the existence of a system which, through simple breathing techniques, can significantly modulate the energy metabolism of our body. This knowledge would provide groundbreaking discoveries in the field of medicine and psychology of human health.

Observed breathing techniques can find practical application also in improving health as process support treatment, for example in people with cardiac disorders. These techniques can also be used for people working in high occupational risk, often in dangerous situations. People under stress react inadequately to the situation: the pulse increases up to 160 beats per minute, and the work of the nervous system is disturbed. Some breathing techniques could easily help to better control stress in dangerous situations, balance the heart rate and calm down in nervous circumstances.

In addition to affecting the energy system of the human body, the impact of concentration techniques on personality, behavior, emotions, motivation, cognition and mental state has been empirically demonstrated in many different studies (see Różycka-Tran \& Tran, 2014, for review). However, health consequences of ETS activation in both psychological and physiological spheres must be investigated in future studies. Modern research integrates Eastern tradition and Western science, that medical students study (Maśliński \& Ryżewski, 2009), see Figure 2.

\section{LIMITATIONS AND FUTURE STUDIES}

Despite the observations, we did not have the proper equipment to prove beyond any doubt the existence of an ETS, postulated by the traditional medicine of the East. We only observed and described significant cardiovascular changes which can only suggest the activation of the ETS, referring to the theory. However, it is necessary to conduct more appropriate research in Western medical facilities to confirm the existence of an additional system regulating the flow of energy in the human body. Future studies should be conducted to explain all possible mechanisms of the postulated energy system.

In future studies we would like to investigate three aspects of the energy system in the human body: "storage" - adipose tissue; "potential" - blood, 
which contains all substrates essential for energy production (glucose and oxygen); and "Qi" (Chinese medicine term) or "vis vitalis" (old European term), i.e. adenosine triphosphate dissociation and in consequence electron movement in connective tissue (CT) meridians, and more precisely the primo vessel system (PVS). What is more, light and electrons from gasotransmitters could be treated as "info-transmitters" acting on adrenergic and cholinergic neurotransmitters, known to Western medicine, causing an adequate reaction. However, such hypotheses must be confirmed empirically.

Further research about ETS could discover and describe another dimension of human functioning. Like the discovery of X-ray radiation, registration of the ETS must lead to a change in the current scientific worldview. The implications of new knowledge require rethinking old ideas to create a new broader context. Although such a challenge can cause intellectual tension, a scientific paradigm change could bring new explanatory causes of human functioning underlying both individual and social phenomena. Future studies seem to be worth conducting also because the TCM has just been recognized by the World Health Organization (WHO) as an effective treatment method.

\section{ACKNOWLEDGEMENTS}

We would like to thank the Master Nguyễn Khắc Phấn and Thiên Môn Đao adepts for presenting many times their skills and participating in studies. Also we would like to thank Dr. Dương Đức Hoàng from the National Hospital of Geriatrics in Hanoi for valuable advice and help. We thank a lot Capt. Trần Anh Quân for opening the gate to the East Asia and hidden knowledge.

\section{ENDNOTES}

1 All recorded material is available: joanna.tran@ug. edu.pl

$2 \mathrm{~A}$ rapid change in blood pressure in adept 1 (aged 22, three years practice) was observed within a very short time, i.e. an increase of $45 \mathrm{mmHg}$ in systolic pressure and $60 \mathrm{mmHg}$ in diastolic pressure within one minute, followed by a rapid decrease, also occurring within one minute. Similarly, in the case of adept 2 (aged 28, five years practice), there was a rapid decrease in systolic blood pressure by $78 \mathrm{mmHg}$ and diastolic blood pressure by $26 \mathrm{mmHg}$ within 2 minutes, with a simultaneous registration of heart rate of up to 106 bpm; in the case of adepts 3 (age 19, three years practice) and 4 (age 27, five years practice), all parameters were increased (heart rate of $108 \mathrm{bpm}$ ).

\section{REFERENCES}

Bower, J. E., \& Irwin, M. R. (2016). Mind-body therapies and control of inflammatory biology: a descriptive review. Brain, Behavior, and Immunity, 51, 1-11. https://doi.org/10.1016/j.bbi.2015.06.012

Chikly, B., Roberts, P., \& Quaghebeur, J. (2016). Primo vascular system: a unique biological system shifting a medical paradigm. Journal of the American Osteopathic Association, 116, 11-21. https:// doi.org/10.7556/jaoa.2016.002

Dada, R., Kumar, S. B., Chawla, B., Bisht, S., \& Khan, B. (2016). Oxidative stress induced damage to the paternal genome and impact of meditation and yoga on incidence of childhood cancer. Asian Pacific Journal of Cancer Prevention, 17, 4517-4525.

Darras, J. C., de Vernejoul, P., \& Albarede, P. (1992). Nuclear medicine and acupuncture: A study on the migration of radioactive tracers after injection at acupoints. American Journal of Acupuncture, 20, 243-256.

Dorfer, L., Moser, M., Spinder, K., Bahr, F., EgarterVigl, E., \& Dohr, G. (1998). 5200-year-old acupuncture in Central Europe? Science, 282, 242-243. https://doi.org/10.1126/science.282.5387.239f

Gajewski, M., Laskowska-Bożek, H., Maśliński, S., \& Ryżewski, J. (1991). Increase in the expression of muscarinic cholinergic receptors in isolated, neonatal rat cardiac myocytes treated with potassium cyanide. Acta Biochimica Polonica, 38, 61-65.

Gajewski, M., Laskowska-Bożek, H., Moutiris, J., Maśliński, S., \& Ryżewski, J. (1993). Enhanced responsiveness of rat cardiac myocytes to muscarinic cholinergic stimulation during chemicallyinduced hypoxia. Acta Neurobiologiae Experimentalis, 53, 79-91.

Gajewski, M., \& Maśliński, S. (2012). Is connective tissue the fourth system regulating the body's energy homeostasis? Reumatologia/Rheumatology, 50, 187-192.

Gajewski, M., Maślinski, S., Rzodkiewicz, P., \& Wojtecka-Łukasik, E. (2013). Gas-therapy in rheumatoid arthritis treatment: When West meets East actual medical concepts with ancient world ideas. In $\mathrm{H}$. Matsuno (Ed.), Innovative Rheumatology (pp. 189-213). London: IntechOpen.

Gajewski, M., Szczepanik, S., Wysocki, Ł., Sygitowicz, G., Gajewska, J., Pachecka, J., \& Maśliński, S. (2006). Connective tissue as the fourth system regulating homeostasis (in polish). Życie Weterynaryjne, 81, 519-529.

Hui, B., Pei-Jing, R., \& Liang, L. I. (2010). Effects of different acupuncture stimulation on NO content in acupoints areas. Journal of Traditional Chinese medicine, 30, 25-29. https://doi.org/10.1016/S02546272(10)60008-8

Irwin, M. R., Olmstead, R., Breen, E. C., Witarama, T., Carrillo, C., Sadeghi, N., Arevalo, J. M., Ma, J., Nicassio, P., Bootzin, R., \& Cole, S. (2015). Cogni-
An energy system in the human body 
Michał Gajewski, Joanna RóżyckaTran, Hao van Le tive behavioural therapy and tai chi reverse cellular and genomic markers of inflammation in late-life insomnia: a randomized controlled trial. Biological Psychiatry, 78, 721-729. https://doi. org/10.1016/j.biopsych.2015.01.010

Kataoka, Y., Cui, Y., Yamagata, A., Niigaki, M., Hirohata, T., Oishi, N., \& Watanabe, Y. (2001). Activitydependent neural tissue oxidation emits intrinsic ultraweak photons. Biochemical and Biophysical Research Communications, 285, 1007-1011. https:// doi.org/10.1006/bbrc.2001.5285

Khattab, K., Khattab, A. A., Ortak, J., Richardt, G., \& Bonnemeier, H. (2007). lyengar yoga increases cardiac parasympathetic nervous modulation among healthy yoga practitioners. Evidence-based Complementary and Alternative Medicine, 4, 511517. https://doi.org/10.1093/ecam/nem087

Kobayashi, M., Kikuchi, D., \& Okamura, H. (2009). Imaging of ultraweak spontaneous photon emission from human body displaying diurnal rhythm. PLoS One, 4, e6256. https://doi.org/10.1371/journal.pone.0006256

Kobayashi, M., Takeda, M., Sato, T., Yamazaki, Y., Kaneko, K., Ito, K., Kato, H., \& Inaba, H. (1999). In vivo imaging of spontaneous ultraweak photon emission from a rat's brain correlated with cerebral Energy metabolism and oxidative stress. Neuroscience Research, 34, 103-113. https://doi. org/10.1016/s0168-0102(99)00040-1

Kumar, S. B., Yadav, R., Yadav, R. K., Tolahunase, M., \& Dada, R. (2015). Telomerase activity and cellular aging might be positively modified by a Yogabased lifestyle intervention. Journal of Alternative and Complementary Medicine, 21, 370-372. https:// doi.org/10.1089/acm.2014.0298

Langevin, H. M., Churchill, D. L., \& Cipolla, M. J. (2001). Mechanical signaling through connective tissue: a mechanism for the therapeutic effect of acupuncture. FASEB Journal, 15, 2275-2282. https://doi.org/10.1096/fj.01-0015hyp

Langevin, H. M., \& Yandow, J. A. (2002). Relationship of acupuncture points and meridians to connective tissue planes. Anatomical Record, 269, 257265. https://doi.org/10.1002/ar. 10185

Lee, M. S., Lee, Y. H., Shin, B. C., Jeong, D. M., Kim, M. K., Eo, Y. G., \& Ko, S. B. (2005). Is there any energy transfer during acupuncture? American Journal of Chinese Medicine, 33, 507-512. https:// doi.org/10.1142/S0192415X05003107

Lee, C., Seol, S. K., Lee, B. C., Hong, Y. K., Je, J. H., \& Soh, K. S. (2006). Alcian blue staining method to visualize bonghan threads inside large caliber lymphatic vessels and x-ray microtomography to reveal their microchannels. Lymphatic Research and Biology, 4, 181-190. https://doi.org/10.1089/lrb. 2006.4402

Lee, C., Yang, J. M., Yi, S. H., Cho, H. J., Kang, M. J., Yang, J. S., \& Soh, K. H. (2004). Biophoton emission from patients with a cold. Journal of International Society of Life Information Science, 22, 362-365.

Ma, S. X., Li, X. Y., Sakurai, T., \& Pandjaitan, M. (2007). Evidence of enhanced non-enzymatic generation of nitric oxide on the skin surface of acupuncture points: an innovative approach in humans. Nitric Oxide: Biology and Chemistry, 17, 60-68. https:// doi.org/10.1016/j.niox.2007.05.004

Maśliński, S., \& Ryżewski, J. (Eds.) (2009). Patofizjologia. Podręcznik dla studentów medycyny [Pathophysiology. Handbook for students of medicine]. Warszawa: PZWL Wydawnictwo Lekarskie.

Mustafa, A. K., Gadalla, M. M., \& Snyder, S. H. (2009). Signaling by gasotransmitters. Science Signaling, 2, re2. https://doi.org/10.1126/scisignal.268re2.

Niggli, H. J., Tudisco, S., Privitera, G., Applegate, L. E., Scordino, A., \& Musumeci. F. (2005). Laser-ultraviolet-A-induced ultraweak photon emission in mammalian cells. Journal of Biomedical Optics, 10, 024006. https://doi.org/10.1117/1.1899185

Oke, S. L., \& Tracey, K. J. (2009). The inflammatory reflex and the role of complementary and alternative medical therapies. Annals of the New York Academy of Sciences, 1172, 172-180. https://doi. org/10.1196/annals.1393.013

Pavlov, V. A., \& Tracey, K. J. (2012). The vagus nerve and the inflammatory reflex - linking immunity and metabolism. Nature Reviews Endocrinology, 8, 743-754. https://doi.org/10.1038/nrendo.2012.189

Revsbech, I. G., Shen, X., Chakravarti, R., Jensen, B. J., Thiel, B., Evans, A. L., Kindberg J., Frobert, O., Stuehr, D. J., Kevil, C., \& Fago, A. (2014). Hydrogen sulfide and nitric oxide metabolites in the blood of free-ranging brown bears and their potential roles in hibernation. Free Radical Biology and Medicine, 73, 349-357. https://doi.org/10.1016/j.freeradbiomed.2014.05.025

Różycka, J., \& Tran, A. Q. (2012). Effect of self-regulation techniques on psychophysical processes. Research in Thien Mon Dao martial art school (in Polish). Gdańskie Studia Azji Wschodniej, 1, 69-83. Różycka-Tran, J., \& Tran, A. Q. (2014). Self-regulation techniques in Vietnamese Zen Truc Lam monastery. Gdańskie Studia Azji Wschodniej, 6, 123-133.

Schutgens, F. W. G., Neogi, P., van Wijk, E. P. A., van Wijk, R., Wikman, G., \& Wiegant F. A. C. (2009). The influence of adaptogens on ultraweak biophoton emission: a pilot-experiment. Phytotherapy Research, 23, 1103-1108. https://doi.org/10.1002/ ptr.2753

Singh, V. P., Khandelwal, B., \& Sherpa, N. T. (2015). Psycho-neuro-endocrine-immune mechanisms of action of yoga in type II diabetes. Ancient Science of Life, 35, 12-17. https://doi.org/10.4103/02577941.165623

Slawinski J. (2005). Photon emission from perturbed and dying organisms: biomedical perspetives. Forschende Komplementärmedizin und Klassische 
Naturheilkunde, 12, 90-95. https://doi.org/10.1159/ 000083971

Soh, K. S. (2004). Bonghan duct and acupuncture meridian as optical channel of biophoton. Journal of the Korean Physical Society, 45, 1196-1198.

Stefanov, M. (2012). Critical review and comments on B. H. Kim's work on the primo vascular system. Journal of Acupuncture and Meridian Studies, 5 , 241-247. https://doi.org/10.1016/j.jams.2012.07.008

Stefanov, M., \& Kim, J. (2012). Primo vascular system as a new morphofunctional integrated system. Journal of Acupuncture and Meridian Studies, 5, 193-200. https://doi.org/10.1016/j.jams.2012.07.001

Stefanov, M., Potroz, M., Kim, J., Lim, J., Cha, R., \& Nam, M. H. (2013). The primo vascular system as a new anatomical system. Journal of Acupuncture and Meridian Studies, 6, 331-338. https://doi. org/10.1016/j.jams.2013.10.001

Sun, Y., Wang, C., \& Dai, J. (2010). Biophotons as a neural communication signals demonstrated by in situ biophoton autography. Photochemical \& Photobiological Sciences, 9, 315-322. https://doi. org/10.1039/b9pp00125e

Szabo, C. (2010). Gaseotransmitters: new frontiers for translational science. Science Translational Medicine, 2, 54-59. https://doi.org/10.1126/scitransImed.3000721

Takewaki, M., Harris, M., Uemura, K., Ueno, T., Hoshino, E., Shiotani, A., Pappas, T. N., \& Takahashi T. (2003). Dual effects of acupuncture on gastric motility in conscious rats. American Journal of Physiology. Regulatory, Integrative and Comparative Physiology, 285, 862-872. https://doi.org/10.1152/ ajpregu.00715.2002

Takewaki, M., Strickland, C., Fukuda, H., Tsuchida, D., Hoshino, E., Pappas, T. N., \& Takahashi, T. (2005). Effects of acupuncture on vasopressin-induced emesis in conscious dogs. American Journal of Physiology. Regulatory, Integrative and Comparative Physiology, 288, 401-408. https://doi.org/10.1152/ ajpregu.00344.2004

Tracey, K. J. (2009). Reflex control of immunity. Nature Reviews Immunology, 9, 418-428. https://doi. org/10.1038/nri2566

Unger, T., Paulis, L., \& Sica, D. A. (2011). Therapeutic perspectives in hypertension: novel means for renin-angiotensin aldosterone system modulation and emerging device-based approaches. European Heart Journal, 32, 2739-2747. https://doi. org/10.1093/eurheartj/ehr253

van Wijk, E. P. A., Koch, H., Bosman, S., \& van Wijk, R. (2006). Anatomic characterization of human ultraweak photon emission in practitioners of transcendental meditation (TM) and control subjects. Journal of Alternative and Complementary Medicine, 12, 31-38. https://doi.org/10.1089/acm.2006.12.31

Vijayaraghava, A., Doreswamy, V., Narasipur, O.S., Kunnavil, R., \& Srinivasamurthy, N. (2015). Effect of yoga practice on levels of inflammatory markers after moderate and strenuous exercise. Journal of Clinical and Diagnostic Research, 9, CC08-CC 12. https://doi.org/10.7860/JCDR/2015/12851.6021

Vinay, A. V., Venkatesh, D., \& Ambarish, V. (2016). Impact of short-term-practice of yoga on heart rate variability. International Journal of Yoga, 9, 62-66. https://doi.org/10.4103/0973-6131.171714

Wanga, Z., Wanga, N., Lia, Z., Xiaoa, F., \& Daia, J. (2016). Human high intelligence is involved in spectral redshift of biophotonic activities in the brain. PNAS, 113, 8753-8758. https://doi. org/10.1073/pnas. 1604855113

Włodarski, J., \& Stankiewicz, J. (2012). "Boxing from Putna" as martial art. Practical meaning of the style in the period of the Taiping and Boxer Rebellions in China (in polish). Gdańskie Studia Azji Wschodniej, 2, 12-28.
An energy system in the human body 